\title{
Avaliação de composições de concreto autoadensável a partir da distribuição granulométrica e de parâmetros de graduação de agregados
}

\author{
Evaluation of self-compacting concrete \\ compositions based on particle size \\ distribution and aggregates \\ grading parameters
}

Cássia Vanessa Albuquerque de Melo ${ }^{1}$, Paulo César Correia Gomes ${ }^{1}$, Karoline Alves de Melo Moraes ${ }^{1}$

\footnotetext{
${ }^{1}$ Laboratório de Estruturas e Materiais (LEMA/CTEC/UFAL), Campus A. C. Simões, s/n, Maceió, Alagoas, Brasil. e-mail: cassiamelo@ctec.ufal.br, pgomes@ctec.ufal.br,kamm@ctec.ufal.br
}

\section{RESUMO}

O concreto autoadensável (CAA) tem sido produzido por diferentes métodos de dosagem. Alguns são baseados na determinação da pasta e do esqueleto granular para o alcance da autoadensabilidade. A busca por empacotamento de agregados com baixo índice de vazios, que leva a uma redução do volume de pasta, tem sido o ideal, mas este modelo pode não ser o melhor para o CAA. Sistemas de partículas com reduzidos vazios e teor de pasta pode comprometer a autoadensabilidade do CAA. Por outro lado, composições de agregados com dosagens igualitárias entre partículas grossas e finas têm sido proposto com sucesso. Neste contexto, o artigo visa analisar composições de agregados com dosagens de agregados graúdos e miúdos equiparados, avaliando suas distribuições granulométricas contínuas e descontínuas, além de determinar parâmetros de graduação, que possam influenciar e contribuir para o alcance da autoadensabilidade do CAA. As propriedades de autoadensabilidade foram verificadas pelos testes de espalhamento, índice de estabilidade visual (IEV), funil V e caixa L. As propriedades determinadas no estado endurecido foram: resistência à compressão, módulo de elasticidade estático, absorção de água por imersão, índice de vazios e massa específica. Para isso, foram utilizados corpos-de-prova cilíndricos $(10 \mathrm{~cm}$ x $20 \mathrm{~cm})$. Os resultados desta pesquisa mostraram que os parâmetros de graduação de agregados, obtidos para cada proporção e distribuição granulométrica das composições de agregados estudadas, ressaltaram o efeito da presença de diâmetros de partículas miúdas em relação às partículas graúdas, podendo-se perceber a contribuição desses parâmetros na obtenção de distribuições contínuas e descontínuas mais fechadas para concreto autoadensável em atendimento às propriedades no estado fresco e endurecido.

Palavras-chave: Composições de agregados, Curvas granulométricas, Concreto autoadensável, Parâmetros de graduação.

\begin{abstract}
The self-compacting concrete (SCC) has been produced by different dosage methods. Some are based on the determination of paste and granular skeleton to achieve self-compactability. The search for aggregate packing with low voids content, which leads to a reduction in the paste volume, has been ideal. However, this model may not be the best for SCC. Particle systems with reduced voids and paste content can compromisse SCC self-compactability. On the other hand, compositions of aggregates with equal dosages between coarse and fine particles have been successfully proposed. In this context, the article aims to analyze aggregate compositions with dosages of similarly of coarse and fine aggregate, evaluating their continuous and discontinuous particle size distributions, in addition to determining graduation parameters, which can influence and contribute to the achievement of SCC self-compactability. The self-compacting properties were verified by the slump flow, visual stability index (VSI), V-funnel and L-box tests. The properties determined in the hardened state were: compressive strength, static elasticity module, water absorption by immersion, voids content and
\end{abstract}


specific mass. For this, it were used especimes cylinders $(10 \mathrm{~cm}$ x $20 \mathrm{~cm})$. The results of this article showed that the graduation parameters of aggregates, obtained for each proportion and particle size distribution of the studied aggregate compositions the effect of the presence of fine particle diameters in relation to large particles, which can be clearly seen. the contribution of these parameters in the continuous and discontinuous distributions more closed for self-compacting concrete in compliance with the properties in the fresh and hardened state.

Keywords: Aggregates composition, Grading curves, Self-compacting concrete, Grading parameters.

\section{INTRODUÇÃO}

O desempenho dos concretos é influenciado pelas características e composição da estrutura granular. A distribuição, quantidade, dimensão e forma dos agregados contribuem para o contato e atrito entre as partículas, que podem enrijecer o sistema granular, prejudicando a fluidez do concreto $[1,2]$. Também é sabido que tal propriedade é afetada negativamente pelos efeitos de massa e pela baixa área superficial de partículas mais grossas. FAROKHZAD et al. [3] foram bem enfáticos ao constatar em seus estudos com graduações de agregados que, mantendo o volume de pasta constante, uma dada graduação com maior área específica demanda maior volume de pasta para envolver todas as partículas mais finas e em graduações de agregados com tamanhos de partículas mais grossas, em que essa área é menor, o volume de pasta é suficiente para envolvê-las e promover uma melhor interligação. Tratando-se de concreto autoadensável (CAA), esta interferência na fluidez é bastante significativa pois sua composição deve ser altamente fluida e de viscosidade moderada [4].

Estudos demonstram que a ausência de partículas menores de agregados dificulta a movimentação de agregados de dimensões maiores [5]. Por outro lado, quando em excesso, a quantidade de partículas pequenas pode requerer uma maior quantidade de pasta de cimento para promover o afastamento dos grãos, tornando a fluidez do concreto reduzida [2, 6]. GHODDOUSI et al. [7] afirmam que este aumento da quantidade de partículas pequenas, estando além do preenchimento dos vazios entre as partículas maiores, pode reduzir o empacotamento granular e, consequentemente, aumentar o índice de vazios. Alguns autores têm buscado estudar os fatores que influenciam na eficiência do empacotamento, como exemplo, a relação dos tamanhos dos grãos entre diâmetros de partículas maiores (DL) e menores (Ds) para o alcance de empacotamento ideal [2, $8,9]$. De fato, para resultar no empacotamento máximo, existem outros parâmetros envolvidos, além do tamanho dos grãos, entre eles, morfologia, efeito parede e densidade das partículas, que precisam ser exploradas [10].

Para DE LARRARD [11], a interação das partículas é apresentada com base nas dimensões dos diâmetros, tendendo a uma interação parcial das partículas quando as frações granulométricas são mais próximas. Isso significa que, tanto a proporção adequada de partículas de diâmetros diferentes, quanto a relação entre diâmetros maiores e menores, são relevantes, para que possam determinar um empacotamento ótimo para as misturas de concreto. Sob o aspecto da interação entre as partículas, devido às suas proximidades, quando o diâmetro d1 dos grãos não é muito maior que o diâmetro d2 $(\mathrm{d} 1 \geq \mathrm{d} 2)$, considera-se o efeito parede. Este mesmo efeito ocorre entre partículas de frações (ou classes) distintas, mas que a diferença de tamanho não é elevada, o que promove menor densidade de empacotamento, pois na parede do grão de maior diâmetro encontra-se uma zona na qual ocorre a perturbação em virtude dos vazios existentes [11]. Conforme De Larrard [11], denomina-se interação parcial, quando composta por dois efeitos: o efeito de parede e o efeito de afastamento.

Isso corrobora com a ideia de DAMINELLI [8] e MOOBERG-BUSTNESS et al. [12] ao mostrarem que, quando se torna menor a diferença entre os diâmetros das partículas, menor a densidade de empacotamento. Neste aspecto, destacam-se as distribuições granulométricas contínuas como àquelas que reduzem a densidade relativa, ao contrário das distribuições descontínuas que, apesar de diminuir a porosidade do sistema granular, pode levar a instabilidade das misturas. Para tanto, a quantidade de partículas com diâmetros menores no CAA, representativas dos agregados miúdos e dos finos também contidos na mistura, é maior, o que faz com que haja uma maior separação entre as partículas de diâmetros maiores, conforme Mehdipour e KHAYAT [13], Figura 1. De fato, há uma continuidade da distribuição granulométrica na Fig. 1b (com o afastamento das partículas maiores resultante das partículas menores), e uma descontinuidade na Fig. 1a (com as partículas de tamanhos maiores estando menos afastadas em misturas de concreto comum, onde ocorre maior fricção das partículas graúdas e miúdas, de uma estrutura mais compacta.

A Figura 1 mostra a diferença entre o estado de máxima densidade de empacotamento e o estado de taxa de fluxo de massa máximo representado em (a) e (b), respectivamente, considerando duas situações onde o teor de finos influencia significativamente na facilidade de movimentação de partículas graúdas e alivia a ação de interligação entre elas. Basicamente, esta representação mostra claramente que a predominância de 
partículas finas numa composição de agregados para concreto autoadensável favorece suas propriedades de autoadensabilidade. Isso recai claramente na afirmação de MEHDIPOUR e KHAYAT [13], ao declararem que a garantia da resistência da suspensão cimentícia (concentração de fração do esqueleto granular na pasta de cimento) à deformação é promovida pelo efeito de interligação das partículas otimizadas. É na busca por melhores dosagens de misturas, que estudos como de LOPES et al. [11] têm se dedicado à otimização de novas formulações de faixas granulométricas dos componentes do concreto, a fim de promover maior preenchimento dos vazios. Vale salientar que a participação do aditivo superplastificante age também na redução de aglomeração de partículas finas, que tendem a gerar maior porosidade na argamassa [14].

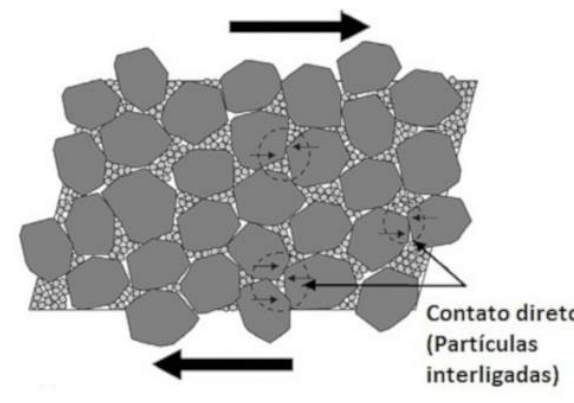

(a)

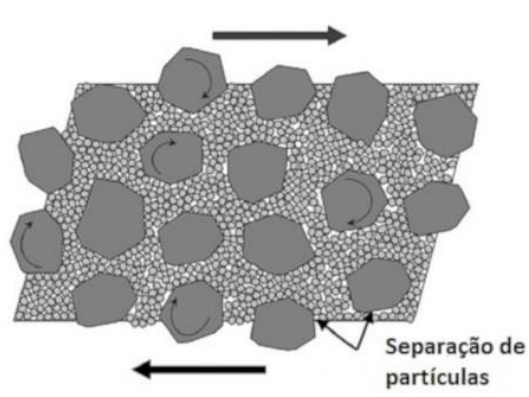

(b)

Figura 1: Imagem de empacotamento máximo de uma mistura comum (a) e estado de taxa de fluxo de massa máximo (b) [13]

A fase agregado deve proporcionar um esqueleto granular com proporções e distribuições de agregados miúdos e graúdos com configuração do arranjo granular compatível para autoadensabilidade do CAA [5]. Estudos do arranjo granular de argamassas, aplicando modelos de empacotamento de partículas, foram realizados por HERMANN et al. [14], considerando as fases matriz e o arranjo seco.

Já a água contida no concreto fresco pode ser tanto a que preenche os vazios entre as partículas sólidas quanto a água em excesso que forma um filme de água na superfície dessas partículas e contribui para a fluidez do concreto [15]. Do ponto de vista reológico, uma mistura de concreto pode ser vista em duas fases: as inclusões mais grossas, ou seja, as partículas de agregados dispersas em uma fase contínua, sendo esta composta por um fluido de suspensão, sendo essa a fase que consiste, na maioria dos casos, na mistura de água e pós cimentícios [16]. Muitos resultados de pesquisas científicas, na busca por concretos mais fluidos, têm obtido baixas estabilidades de misturas, em virtude de a coesão ser insuficiente [17].

São escassos os estudos publicados acerca da influência da dominância da distribuição e dimensões dos grãos de agregados na autoadensabilidade e nas propriedades mecânicas do CAA. As pesquisas geralmente não avaliam a dominância de determinadas frações granulométricas nem tampouco a distância de separação das predominâncias de partículas graúdas e miúdas em distribuições, quer seja do tipo contínua ou descontínua. $\mathrm{O}$ que se tem avaliado quando se trata de agregados e determinado como parâmetros de misturas para o CAA, são as relações de volume de determinada dimensão de agregado com o volume total de agregados e com o volume do concreto. Na literatura, tem-se constatado que a relação volumétrica do agregado miúdo e o total de agregados varia entre $36 \%$ e $60 \%$ : SU et al. [18] e MELO [19] adotaram $53 \%$; TUTIKIAN [20] adotou $52 \%$; LISBOA [21], CAVALCANTI [22], MONTEIRO et al. [23] adotaram $50 \%$. Tais resultados levaram a concluir que a percentagem de agregado graúdo (PAG) tem sido em torno de $50 \%$, também considerada por GOMES [24], é a mais favorável, confirmando o método de OKAMURA [25].

Neste contexto, o artigo tem como objetivo analisar diferentes composições de agregados de distribuições continuas e descontinuas, com dosagens equiparadas de graúdos e miúdos (50\% cada), e seus parâmetros de graduação que influenciaram e contribuíram no alcance da autoadensabilidade do concreto e de suas propriedades mecânicas.

\section{MATERIAIS E MÉTODOS}

O esquema geral do procedimento experimental adotado neste estudo é apresentado na Figura 2, detalhandoo em seguida. 


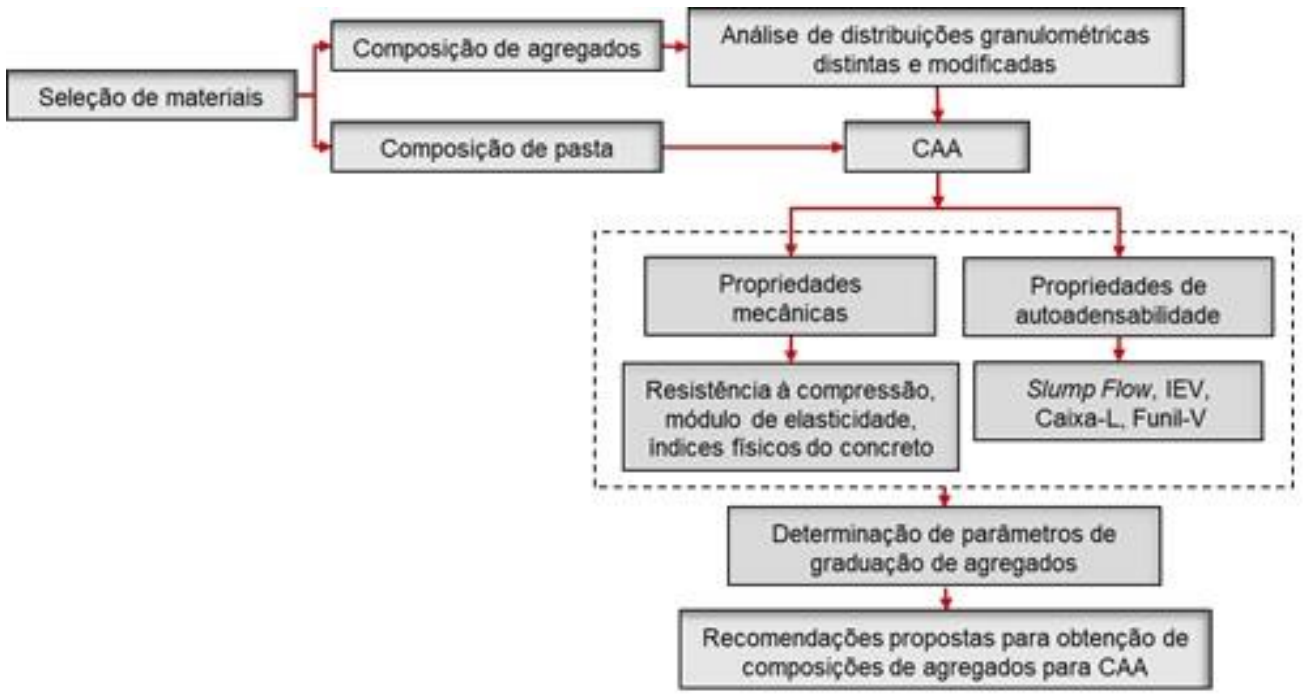

Figura 2: Esquema do procedimento experimental

\subsection{Materiais e composições}

Os materiais utilizados na preparação dos concretos foram: cimento Portland CP II Z - 32, conforme classificado na norma brasileira NBR 16697 [26]. Adição mineral, resíduo de blocos de mármore e granito (RBMG) de massa específica igual a $2650 \mathrm{~kg} / \mathrm{m}^{3}$ e passante na peneira de $\# 300 \mu \mathrm{m}$. O aditivo superplastificante policarboxílico foi utilizado com o percentual de $0,54 \%$. Dois tipos de agregado miúdo foram utilizados, sendo um classificado com granulometria média e codificado por "M", obtido no Rio Paraíba, Estado de Alagoas, e o outro agregado industrial, com granulometria grossa (pó de rocha), codificado por "AI", foram utilizados. Seguindo as recomendações da NBR 7211 [27], os módulos de finura (MF) de "M" e "AI" foram iguais a 2,20 e 2,85, com dimensão máxima de 2,36 e 4,75 mm, respectivamente. Já o agregado graúdo granítico obteve dimensão máxima de 12,5 mm, codificado neste estudo como "B12", teve módulo de finura de 6,21.

As composições binárias de referência, formadas com agregados miúdos (AI e M) e graúdo (B12), foram fixadas na relação agregado miúdo e agregado graúdo igual a 50\%, denominadas AIB12 e MB12. As composições contendo areia industrial (AI), foram formuladas a fim de serem obtidas e avaliadas quanto às distribuições granulométricas descontínuas (D). Já aquelas contendo agregado miúdo de granulometria média (M) foram formuladas obtendo-se distribuições contínuas $(\mathrm{C})$.

Estas composições base foram modificadas em diferentes peneiras (\#), proporcionando distribuições descontínuas que se deu pela ausência dos grãos nas frações definidas (“d” para agregados miúdos, "D” para agregados graúdos), por exemplo, "d1" - ausência de agregados passantes na \#4,75 mm e retidos na \#2,36 $\mathrm{mm}$; e contínuas que se deu pelo acréscimo de grãos nas frações definidas ("c" miúdos e "C" graúdos), por exemplo, "c1" incremento de agregados na \# 2,36 mm. Estas modificações geraram diferentes distribuições granulométricas e composições de agregados que foram utilizadas para formulação das diferentes dosagens de CAA. Estas diferentes composições de agregados estão apresentadas na Figura 3. 


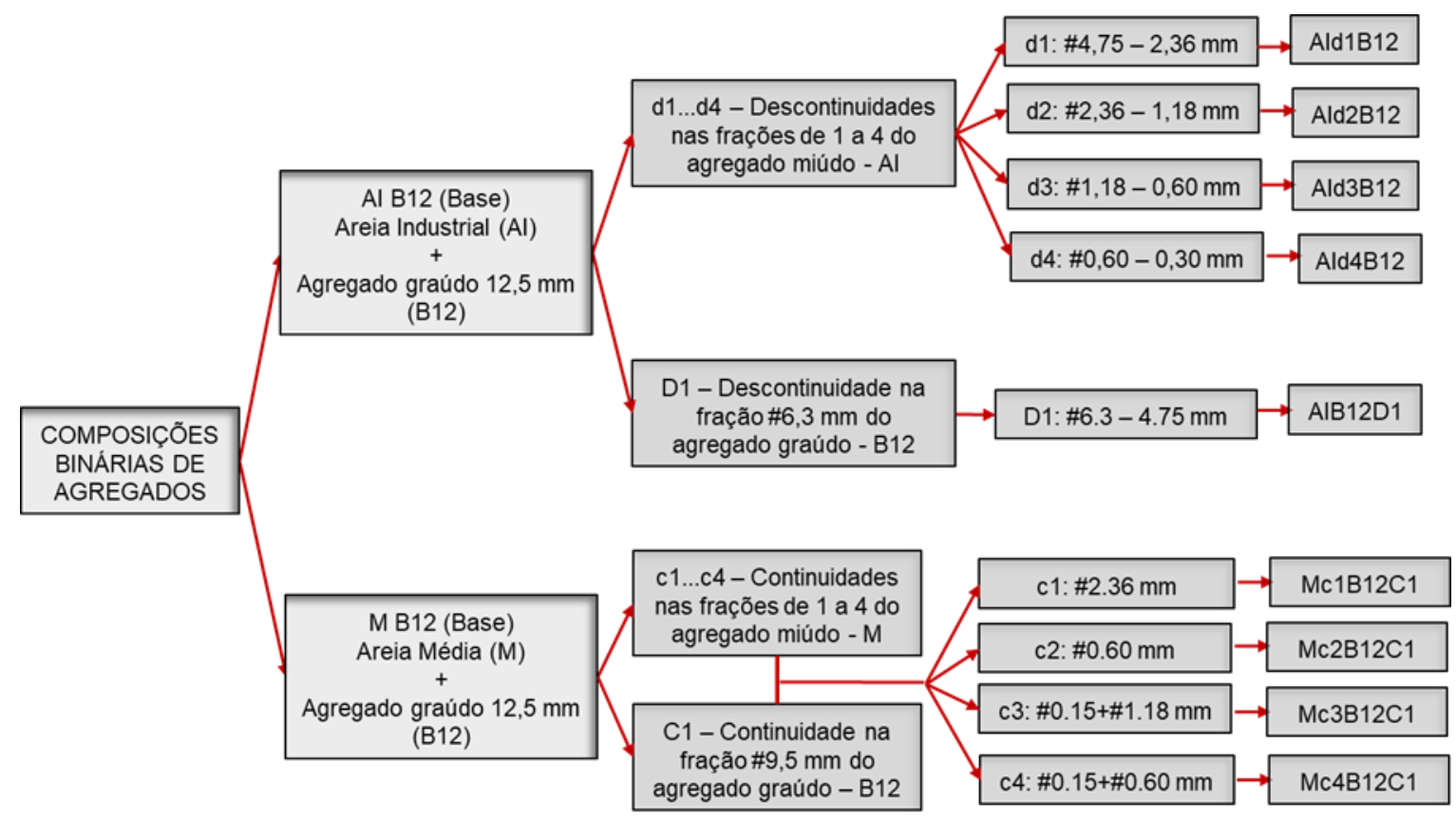

Figura 3: Composições binárias de agregados distintas e modificadas

A formulação dos CAA baseou-se nas duas fases - pasta e esqueleto granular, conforme o método de GOMES [24]. Manteve-se a composição constante para a fase pasta, considerando a relação adição mineral resíduo de mármore e granito em função do cimento $(\mathrm{r} / \mathrm{c})$ igual a 0,5 , como também a relação água/cimento (a/c) de 0,5 . O volume de pasta utilizado foi de $40 \%$ por metro cúbico de concreto [23]. Para a fase granular binária fixou-se em $50 \%$ a relação entre agregado graúdo e miúdo variando apenas a distribuição granulométrica das diferentes composições de agregados. Ao todo foram 9 (nove) traços e 5 (cinco) corpos-de prova cada.

As composições das misturas de concreto formuladas com as composições binárias de agregados base, contendo areia industrial (AI) ou areia natural média (M) e agregado graúdo com dimensão máxima de 12,5 mm, encontram-se na Tabela 1. Os parâmetros de misturas para CAA foram obtidos e apresentados na Tabela 1.

Tabela 1: Dosagem de CAA com composições binárias base.

\begin{tabular}{l|c|c}
\hline MATERIAIS $\left(\mathrm{KG} / \mathbf{M}^{3}\right)$ & CAA COM AIB12 & CAA COM MB12 \\
\hline Cimento & 394 & 394 \\
\hline Resíduo $\mathrm{r} / \mathrm{c}=0,50$ & 197 & 197 \\
\hline Água a/c=0,50 & 197 & 5,9 \\
\hline Superplastificante & 5,9 & - \\
\hline Areia Industrial $(\mathrm{AI})$ & 798 & 807 \\
\hline Areia natural média $(\mathrm{M})$ & - & 807 \\
\hline Agregado graúdo $(\mathrm{B} 12)$ & 798 & 2423,7 \\
\hline Peso da mistura $\left(\mathrm{kg} / \mathrm{m}^{3}\right)$ & 2405 & 0,50 \\
\hline & PARÂMETROS DE DOSAGEM \\
\hline Vag/Vat $\left(\mathrm{m}^{3} / \mathrm{m}^{3}\right)$ & 0,50 & 30 \\
\hline Vag/Vc $\left(\% / \mathrm{m}^{3}\right)$ & 29 & 0,51 \\
\hline Vam $/ \mathrm{Vat}\left(\mathrm{m}^{3} / \mathrm{m}^{3}\right)$ & 0,51 & 30 \\
\hline Vam $/ \mathrm{Vc}\left(\% / \mathrm{m}^{3}\right)$ & 31 & \multicolumn{2}{|c}{} \\
\hline
\end{tabular}

Legenda: Vag - Volume de agregado graúdo; Vat - Volume total de agregado; Vc - Volume de concreto; Vam - Volume de agregado miúdo. 
Os parâmetros de dosagem determinados estão de acordo com os encontrados para misturas de CAA [18-25].

\subsection{Parâmetros de graduação}

Tendo como base a teoria de empacotamento de partículas, considerando-se a influência da presença de partículas miúdas e a contribuição destas no fluxo entre as partículas, estabeleceu-se alguns fatores denominados de parâmetros de graduação de agregados (PGA) para avaliar a relação da configuração do sistema granular com a mobilidade do CAA. Os PGA determinados foram o coeficiente de uniformidade ( Cup) e a predominância de diâmetros de partículas $(P D P)$. Para quantificação destes parâmetros, analisou-se os seguintes fatores: as porcentagens retidas individuais (PRI) em cada fração granulométrica, para determinação de uma razão de predominância dos diâmetros de frações granulométricas graúdas e miúdas; a distribuição granulométrica descontínua e contínua das composições de agregados e a percentagem de agregado graúdo no total de agregados (PAG). Mais detalhes dos PGA podem ser encontrados na literatura [28, 29], sendo para este estudo estabelecido: PAG igual a $50 \%$, índice de vazios e massa unitária da mistura seca de agregados graúdos e miúdos, sendo determinados de acordo com a NBR NM 45 [30] e agregados graúdos de dimensões 12,5 mm.

O coeficiente de uniformidade de partículas (Cup), adimensional, dado pela Eq. 1, mostra os efeitos das graduações das composições de agregados estudadas [3].

$$
\operatorname{Cup}=\frac{D_{60} \%}{D_{10 \%}}
$$

na qual $D_{60 \%}$ é o diâmetro da peneira que passam $60 \%$ de partículas; e $D_{10 \%}$ é o diâmetro da peneira que passam $10 \%$ de partículas.

O parâmetro de predominância de diâmetro de partículas $(P D P)$, proposto pelos autores, é dado pela Eq. 2, adimensional, considera as proporções e as PRI dos grãos pequenos e grossos predominantes:

$$
P D P=\frac{D_{g, \text { médio }}}{D_{p, \text { médio }}}
$$

na qual $D_{\mathrm{g} \text { médio }}$ diâmetro de partículas grossas que apresenta maior percentagem retida individual (PRI) e que diferencie mais que $10 \%$ das demais percentagens de partículas grossas. Caso a diferença seja menor, obtém-se o diâmetro médio referente à média das PRI predominantes na fração grossa; $D_{\mathrm{p} \text { médio }}=$ diâmetro médio de partículas pequenas, apresentando-se PRI maiores que $10 \%$.

\subsection{Ensaios de autoadensabilidade}

Os ensaios no estado fresco realizados para a aceitação do CAA, foram baseados na NBR 15823-1 [31], entre eles: determinação do espalhamento - SF (slump flow test), índice de estabilidade visual (IEV), método da caixa L (habilidade passante - HP) e método do funil-V (viscosidade plástica aparente - VF).

$\mathrm{Na}$ verificação do atendimento da autoadensabilidade, o ensaio de espalhamento foi fundamental por possibilitar a análise dos concretos formulados com distintas composições de agregados. As misturas de concreto que não apresentaram segregação, exsudação e perda de estabilidade visual foram submetidas, posteriormente, aos demais testes de autoadensabilidade supracitados.

Os resultados dos ensaios foram fixados, entre eles: $750 \pm 50 \mathrm{~mm}$ para diâmetro de espalhamento; $9 \pm 1$ segundos para funil V; e entre 0,8 e 1,0 para caixa $\mathrm{L}$.

\subsection{Ensaios no estado endurecido}

Os ensaios de resistência à compressão axial foram realizados para cada formulação de concretos, de acordo com a NBR 5739 [32], aos 28 dias, após a moldagem dos corpos de prova cilíndricos com dimensões (10 cm x $20 \mathrm{~cm}$ ), seguindo as prescrições da NBR 5738 [33]. Foram dois traços distintos: um traço para as 5 misturas de concreto contendo o agregado miúdo "M" e um traço para 6 misturas de concreto contendo a pedra de rocha "AI". Foram considerados 5 corpos-de-prova para cada ensaio. Os valores das resistências à compressão $\left(f_{c m}\right)$, em megapascals, e do módulo de elasticidade estático tangente inicial do concreto (Eci), em gigapascals, também foram obtidos, tomando-se como base os resultados dos ensaios realizados conforme as normas NBR 5739 [32] e NBR 8522 [34], respectivamente. Para os valores de $\mathrm{f}_{\mathrm{cm}}$ e Eci foi aplicado o critério de Grubbs (teste do valor extremo), para decisão do descarte de valores espúrios, admitindo-se um nível de confiança de $95 \%$.

As determinações da absorção de água (A) e do índice de vazios por imersão e fervura (Ivc), ambos em 
percentagem, e a massa específica real dos corpos-de-prova ( $\rho$ r), em kg/m $\mathrm{m}^{3}$, foram realizadas na idade de 28 dias, conforme a norma NBR 9778 [35]. Os resultados foram analisados conforme sugestão de Helene [36] para a classificação dos concretos em função da porosidade e da absorção de água: concretos duráveis - porosidade (Ivc) < $10 \%$ e absorção de água (A) < 4,2\%; concretos normais - porosidade (Ivc) entre 10 e $15 \%$ e absorção de água (A) entre 4,2 e 6,3\%; e concretos deficientes - porosidade (Ivc) $>15 \%$ e absorção de água (A) $>6,3 \%$.

\section{RESULTADOS E DISCUSSÕES}

\subsection{Curvas de distribuições granulométricas de composições de agregados descontínuas e contínuas}

As curvas descontínuas (D) de composição de agregados tendo como base a composição A1B12, estão apresentadas nas Figuras 4 e 5. A Figura 4, contém as curvas granulométricas de composições elaboradas com a descontinuidade de algumas frações da areia industrial (AI) e a Figura 5, contém as curvas granulométricas de composições elaboradas com a descontinuidade do agregado graúdo (B12). Já as curvas contínuas (C) de composição de agregados tendo como base a composição MB12, estão apresentadas na Figura 6. Esta, contém as curvas granulométricas de composições elaboradas com a continuidade de algumas frações da areia de granulação média (M) e do agregado graúdo (B12).

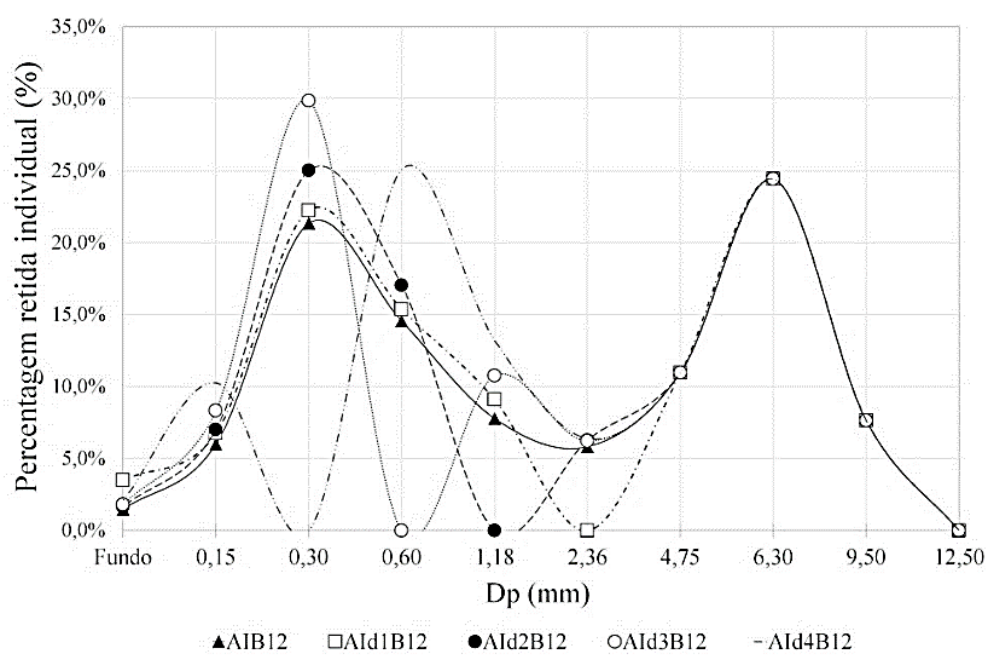

Figura 4: Curvas granulométricas de composições de agregados contínua base (AI B12) e descontínuas em frações miúdas

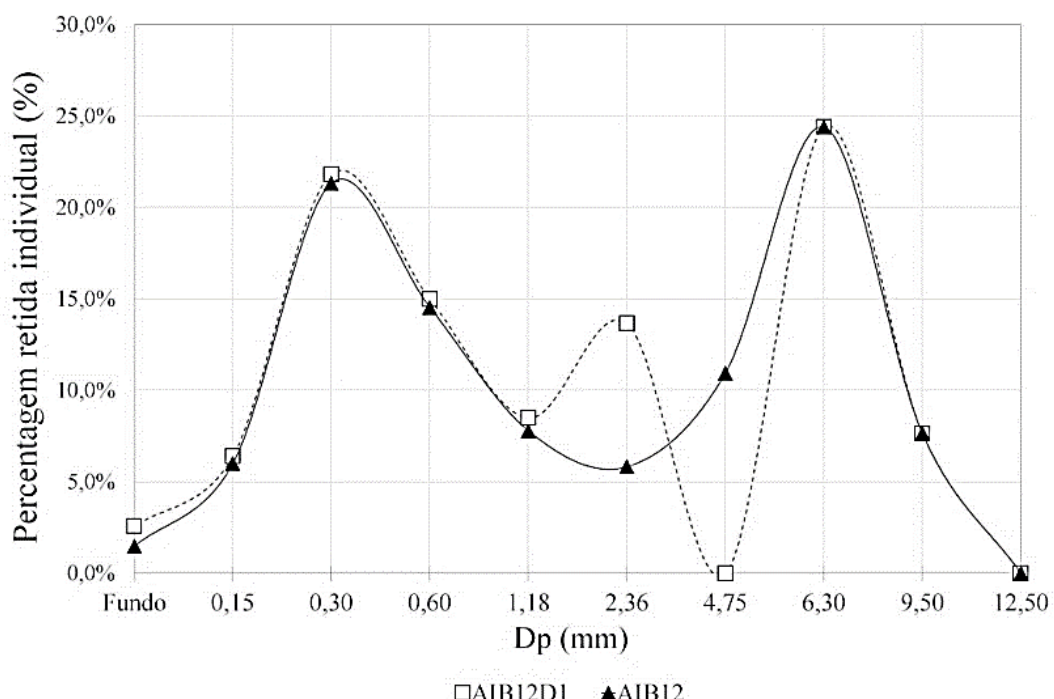

Figura 5: Curva granulométrica de composição de agregados descontínua em fração graúda e a composição base AIB12 


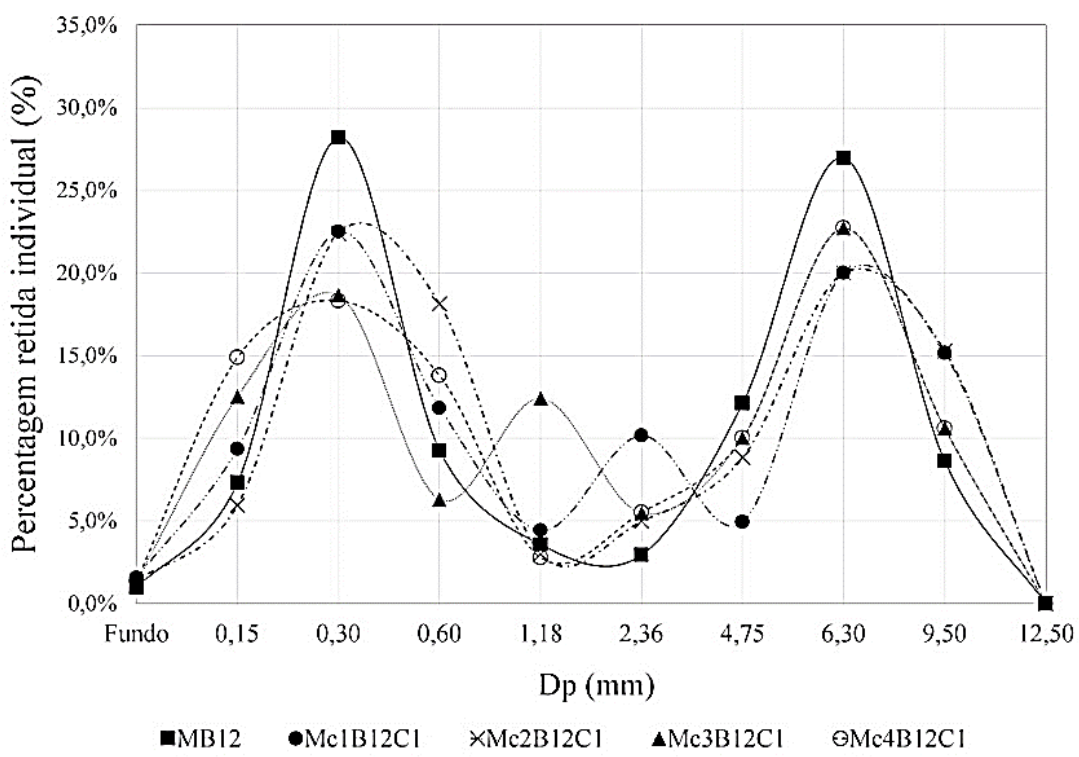

Figura 6: Curvas granulométricas de composições de agregados contínuas base (MB12) e com alteração em frações de agregados miúdo e graúdo

Observa-se nas curvas das composições bases (AIB12 e MB12) que, apesar da menor percentagem de partículas intermediárias (\#1,18 mm - \#4,75 mm), estas contribuíram para a continuidade da granulometria dos agregados, mesmo apresentando uma curva com aspecto descontínuo.

As curvas granulométricas dos agregados nas composições base e modificadas, estas últimas ocorridas nas frações apresentadas conforme Fig. 4, apresentaram picos de predominâncias nas frações de grãos menores, em geral, na fração \#0,30 mm, e na fração de grãos maiores, \#6,3 mm. Toda a extensão granulométrica das composições apresentou porcentagens retidas individuais (PRI) nas frações de grãos miúdos e graúdos dos agregados utilizados, com exceção das composições com gap nas frações: \#0,30 mm; \#0,60 mm; \#1,18 $\mathrm{mm}$; \#2,36 mm (Figuras 4) e \#4,75 mm (Figura 5). Contudo, apesar do gap existente e o incremento nas frações \#1,18 mm e \#2,36 mm, isso não contribuiu para o maior distanciamento dos picos de predominâncias dos grãos relatados, devido a predominância de diâmetros de partículas retidas nas frações menores mais próximas alcançadas pelo balanceamento das PRI. O mesmo ocorreu nas frações do agregado graúdo (B12) das composições contendo areia (M), quando frações vizinhas tiveram suas PRI modificadas devido ao incremento de PRI na fração $\# 9,5 \mathrm{~mm}$, conforme visto na Figura 6.

Além das ressalvas anteriores é mister que o distanciamento de frações menores de agregados miúdos em relação aos agregados graúdos, favorece a teoria de separação de partículas graúdas e miúdas, conforme MEHDIPOUR e KHAYAt [13], Figura 1.

Nota-se, nas Figuras 4, 5 e 6 que, tanto as distribuições contínuas quanto as descontínuas portaram-se com predominâncias de tamanhos de grãos, basicamente, nas mesmas frações, constatando-se sempre a presença da distância entre os picos das partículas finas e grossas e a aproximação dos diâmetros presentes em toda a extensão granulométrica, favorecendo a ocorrência do efeito parede [8, 12]. A partir desse fenômeno, começa a haver interações entre as partículas. Com isso, permite-se com que haja uma maior estabilidade das misturas devido à presença das partículas no esqueleto granular, confirmando o que alguns estudos já têm constatado que a ausência de partículas menores pode dificultar a movimentação dos grãos maiores na mistura [5], e à medida que os diâmetros dos grãos se aproximam, aumenta o efeito parede e, consequentemente, os vazios $[8,12]$.

\subsection{Parâmetros de graduação de agregados para CAA}

As principais características das composições de agregados, considerando a proporção de agregado graúdo e agregado miúdo, em massa, de 50\%/50\%, e dos parâmetros de graduação Cup e PDP, encontram-se na Tabela 2. Tais percentagens são recomendadas na literatura [21-25]. 
Tabela 2: Características das composições de agregados e de parâmetros de graduação.

\begin{tabular}{|c|c|c|c|c|c|}
\hline \multirow{2}{*}{$\begin{array}{c}\text { COMPOSIÇÕES } \\
\text { DE AGREGADOS }\end{array}$} & \multirow{2}{*}{$\begin{array}{l}\text { TIPO DE } \\
\text { DG }\end{array}$} & \multirow{2}{*}{$\begin{array}{l}\text { Iv } \\
(\%)\end{array}$} & \multirow{2}{*}{$\begin{array}{c}\mathrm{Mu} \\
\left(\mathrm{kg} / \mathrm{m}^{3}\right)\end{array}$} & \multicolumn{2}{|c|}{ PARÂMETROS DE GRADUAÇÃO DE AGREGADOS (PGA) } \\
\hline & & & & $\left(\right.$ Cup $\left.=D_{60} / D_{10}\right)$ & (PDP) \\
\hline AIB12 & $\mathrm{C}$ & 31,7 & 1816,7 & $5,18 / 0,34=15,44$ & 14,03 \\
\hline AId1B12 & $\mathrm{D}$ & 31,7 & 1816,3 & $5,18 / 0,29=17,59$ & 14,03 \\
\hline AId2B12 & $\mathrm{D}$ & 31,9 & 1810,4 & $5,18 / 0,32=16,39$ & 14,03 \\
\hline AId3B12 & $\mathrm{D}$ & 31,8 & 1815,0 & $5,18 / 0,30=17,41$ & 8,53 \\
\hline AId4B12 & $\mathrm{D}$ & 33,1 & 1780,8 & $5,18 / 0,27=19,45$ & 9,79 \\
\hline AIB12D1 & $\mathrm{D}$ & 30,9 & 1837,1 & $3,36 / 0,31=10,70$ & 5,80 \\
\hline MB12 & $\mathrm{C}$ & 30,8 & 1830,4 & $5,73 / 0,32=17,88$ & 21,14 \\
\hline $\mathrm{Mc} 1 \mathrm{~B} 12 \mathrm{C} 1$ & $\mathrm{C}$ & 30,9 & 1830,8 & $4,75 / 0,28=16,66$ & 7,27 \\
\hline $\mathrm{Mc} 2 \mathrm{~B} 12 \mathrm{C} 1$ & $\mathrm{C}$ & 30,9 & 1830,4 & $5,47 / 0,34=16,29$ & 17,59 \\
\hline Mc3B12C1 & $\mathrm{C}$ & 29,6 & 1864,6 & $5,26 / 0,25=20,71$ & 17,59 \\
\hline $\mathrm{Mc} 4 \mathrm{~B} 12 \mathrm{C} 1$ & $\mathrm{C}$ & 30,8 & 1832,5 & $5,26 / 0,24=22,19$ & 18,03 \\
\hline
\end{tabular}

Legenda: DG - Distribuição Granulométrica; Iv - Índice de vazios; Mu - Massa Unitária; Cup - Coeficiente de uniformidade de partículas; PDP - Predominância de diâmetro de partículas.

$\mathrm{Na}$ Tabela 2, verifica-se que a diferença entre os valores de Iv e Mu, das composições modificadas, foi pequena em relação aos das bases AIB12 e MB12, além disto, a variação dos valores do Iv, entre $29 \%$ e $33 \%$, e do $\mathrm{Mu}$, entre $1780,8 \mathrm{~kg} / \mathrm{m}^{3}$ e $1864,6 \mathrm{~kg} / \mathrm{m}^{3}$, de todas as composições, não foi relevante, o que se justifica pela mesma proporção de agregados graúdos e miúdos de $50 \% / 50 \%$ adotada em todas elas. Já a diferença dos valores dos PGA foram consideráveis mostrando-se bastante sensíveis às modificações.

As composições de agregados $\mathrm{AId}_{\mathrm{i}} \mathrm{B} 12$ (i de 1 a 4), com gap, no geral, tiveram os valores das Mu menores e o Iv maiores do que a composição base AIB12. A maior variação ocorreu na composição AId4B12, com Mu 1,98\% inferior ao valor da composição AIB12, e Iv 4,42\% superior. Isto pode ter ocorrido porque o gap na fração \#0,30 mm aumentou a PRI na fração \#0,60mm, Figura 4, e resultou numa composição de agregados com percentagem elevada de partículas de tamanhos menores, o que pode ter dificultado o preenchimento dos vazios deixados pelas partículas maiores, elevando-se o índice de vazios. Assim, o Cup aumentou com a diminuição de $\mathrm{D}_{10}$. Já o PDP foi menor, mostrando que houve uma diminuição na predominância de diâmetros de partículas mais grossas. Neste aspecto, quando o diâmetro $\mathrm{D}_{10}$ aumentou suavemente nas composições contendo areia industrial (AI) e agregado graúdo (B12) e o diâmetro $\mathrm{D}_{60}$ manteve-se fixo (vale ressaltar a limitação inicial de manterem-se fixas as frações acima de \#4,75 mm), mostrou-se claramente a influência do diâmetro das frações miúdas no aumento do parâmetro Iv, principalmente quando $\mathrm{D}_{60}$ aumentou e $\mathrm{D}_{10}$ aumentou, resultando em um Cup e PDP menores.

Porém, o mesmo já não ocorreu quando o gap (D1) foi no agregado graúdo B12. A massa unitária (Mu) ficou $1,12 \%$ maior e o Iv $2,52 \%$ menor do que os valores obtidos na composição base AIB12, o que confirma o ocorrido contrário ao da composição AId4B12, com o aumento de partículas menores que \#2,36 $\mathrm{mm}$ e retirada de partículas maiores que $4,75 \mathrm{~mm}$, Figura 4 , que contribuiu para um melhor empacotamento, levando também a diminuição tanto do Cup quanto do PDP.

Quando as modificações ocorreram na mistura base MB12, modificando as partículas $\mathrm{Mc}_{\mathrm{i}} \mathrm{B} 12 \mathrm{C} 1$ (i de 1 a 4), os valores de Mu e dos Iv praticamente não sofreram alterações em relação aos da composição base, com exceção da Mc3B12C1, que apresentou o valor de Mu 1,87\% maior e Iv 3,9\% menor, sendo influenciados pelo aumento de partículas finas, ou seja, pela diminuição de $\mathrm{D}_{10}$ e pelo maior diâmetro $\mathrm{D}_{60}$, aumentando Cup. Nos casos dessas composições com areia média (M), notou-se uma ligeira diminuição de $P D P$ em Mc1B12C1, com a diminuição de $\mathrm{D}_{60}$, ou seja, a predominância de partículas miúdas e o consequente incremento na percentagem retida individual (PRI) na fração \#2,36 mm, contribuiu para a diminuição de PDP (aproximação dos diâmetros predominantes graúdos e miúdos).

Analisando os PGA, observa-se que as modificações nas composições tiveram interferência no arranjo granulométrico e na predominância do diâmetro dos grãos, influenciando no empacotamento, haja vista os efeitos de parede e de afastamento que possam ter ocorridos. 


\subsection{Propriedades dos CAA nos estados fresco e endurecido}

Os resultados dos ensaios de autoadensabilidade dos CAA obtidos, considerando-se os limites preconizados na NBR 15823 - 1 [31], estão contidos na Tabela 3. Os ensaios de slump flow e caixa-L dos concretos CAId2B12, CAIB12D1, CMc1B12C1 e CMc4B12C1 estão apresentados na Figura 7.

Tabela 3: Propriedades de autoadensabilidade dos CAA.

\begin{tabular}{c|c|c|c|c}
\hline \multirow{2}{*}{ COMPOSIÇÕES DE CONCRETO } & \multicolumn{2}{|c|}{ ESPALHAMENTO } & \multirow{2}{*}{$\begin{array}{c}\text { FUNIL-V } \\
\text { VF (s) }\end{array}$} & \multirow{2}{*}{$\begin{array}{c}\text { CAIXA-L (HP) } \\
\text { H2/H1 }\end{array}$} \\
\cline { 2 - 3 } & SF $(\mathbf{m m})$ & IEV & 9,1 & 0,93 (sem bloqueio) \\
\hline CAIB12 & 741 & 0 & 12 & 0,71 (sem bloqueio) \\
\hline CAId1B12 & 609 & 0 & 8,1 & 0,90 (sem bloqueio) \\
\hline CAId2B12 & 715 & 0 & 4,6 & 0,92 (sem bloqueio) \\
\hline CAId3B12 & 748 & 0 & 8,5 & 0,90 (sem bloqueio) \\
\hline CAId4B12 & 706 & 0 & 18 & 1,00 (sem bloqueio) \\
\hline CAIB12D1 & 666 & 0 & 9,5 & 0,92 (sem bloqueio) \\
\hline CMB12 & 745 & 0 & 7,3 & 1,00 (sem bloqueio) \\
\hline CMc1B12C1 & 748 & 0 & 6,0 & 1,00 (sem bloqueio) \\
\hline CMc2B12C1 & 755 & 0 & 5,7 & 0,90 (sem bloqueio) \\
\hline CMc3B12C1 & 825 & 0 & 7,0 & 1,00 (sem bloqueio) \\
\hline CMc4B12C1 & 781 & 0 & 0 &
\end{tabular}

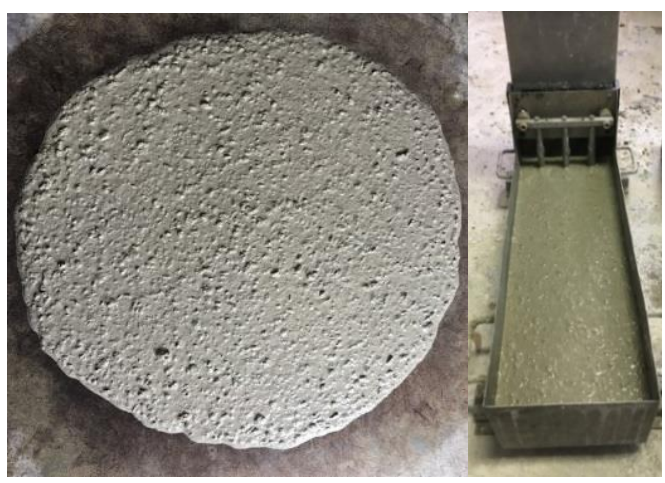

\section{CAId2B12}

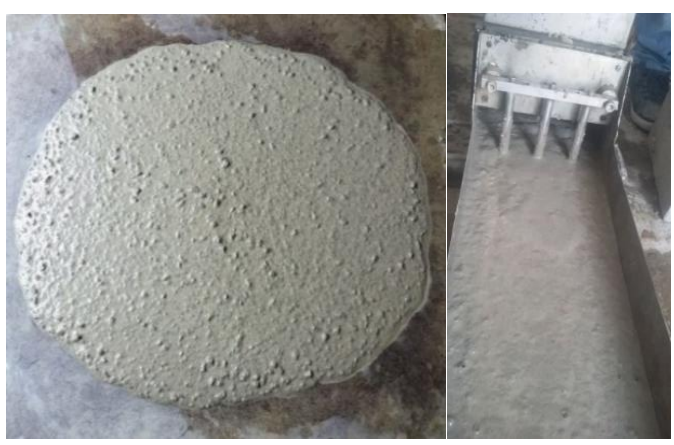

$\mathrm{CMc} 1 \mathrm{~B} 12 \mathrm{C} 1$

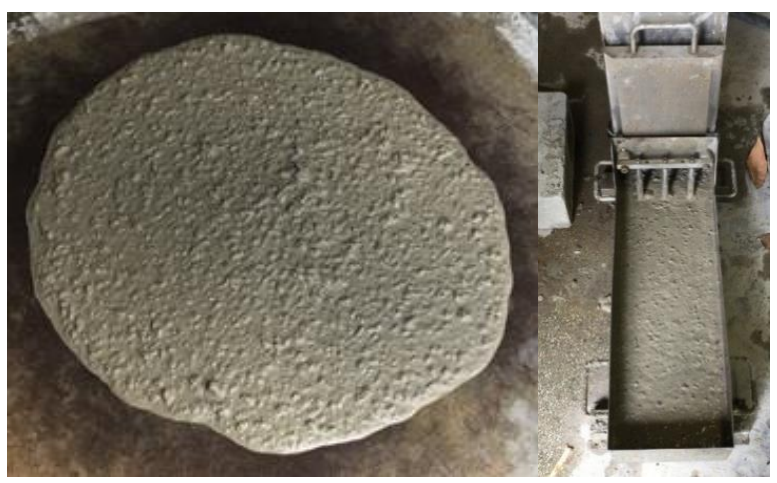

CAIB12D1

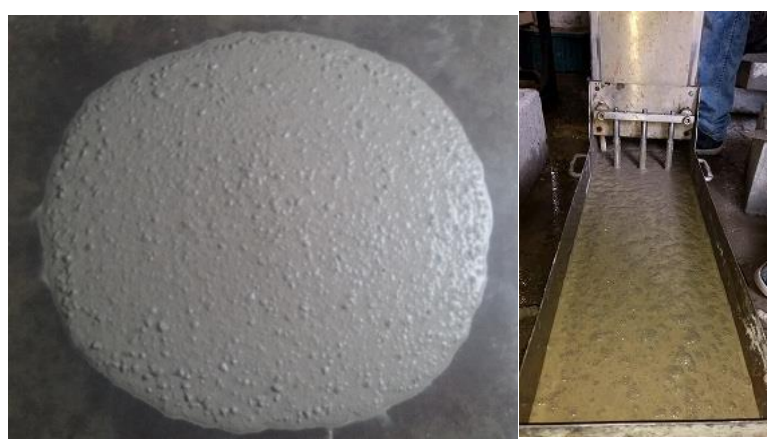

$\mathrm{CMc} 4 \mathrm{~B} 12 \mathrm{C} 1$

Figura 7: Ensaios Slump flow e caixa-L dos CAA. 
Todas as misturas atenderam aos requisitos normativos da NBR 15823 - 1 [31]. Essas misturas se apresentaram altamente estáveis sob fluxo livre, sendo avaliado o índice de estabilidade visual IEV 0. Praticamente, todas as misturas enquadraram-se na classe SF2 (660 a $750 \mathrm{~mm})$, com as seguintes exceções: CAId1B12, que se enquadrou na classe SF1 (550 a $650 \mathrm{~mm}$ ); e CMc3B12C1 e CMc4B12C1, que se enquadraram na classe SF3 (760 a $850 \mathrm{~mm}$ ). Estas misturas se destacaram por obter menores $\mathrm{D}_{10}$ (aumento de Cup) e maiores $P D P$.

As misturas apresentaram resistência ao bloqueio e habilidade passante ao passar pelas três barras de aço da caixa-L, sem segregação, sob fluxo confinado. Tais resultados foram demonstrados pelas relações das alturas $(\mathrm{H} 2 / \mathrm{H} 1)$ maiores que 0,80 , devido a viscosidade moderada. CAId1B12 foi a única mistura que se mostrou mais viscosa em relação às demais, com $\mathrm{HP}<0,80$, devido às mesmas razões analisadas.

No ensaio de funil $\mathrm{V}$, também sob fluxo confinado, praticamente todas as misturas enquadraram-se na classe VF1 (VF < 9), com as exceções de CAId1B12 e CAIB12D1, situando-se na classe VF2 (VF > 9).

Observou-se que o parâmetro $C u p$, especificamente o valor do denominador $\mathrm{D}_{10}$ e a magnitude do parâmetro $P D P$, analisados mutuamente, apresentaram uma influência importante nas propriedades de autoadensabilidade. $\mathrm{O}$ afastamento dos valores de $\mathrm{D}_{10}$ e $\mathrm{D}_{60}$, bem como o aumento do valor de $P D P$, mostraram que há uma influência significativa do teor de finos na estabilidade das suspensões cimentícias promovida pela interligação das frações miúdas e graúdas. $\mathrm{O}$ aumento de $\mathrm{D}_{10}$ e a diminuição de $P D P$, bem como a predominância de partículas miúdas e graúdas, com picos mais próximos, isto é, com curvas granulométricas mais fechadas, pode ter corroborado para a redução da fricção entre as partículas grossas e para o aumento do efeito parede.

As propriedades no estado endurecido estão apresentadas na Tabela 4 e as relações entre $f_{c m}$, A e Ivc na Figura 8. O critério de Grubbs (teste do valor extremo) foi usado, considerando os valores médios de resistências à compressão $\left(\mathrm{f}_{\mathrm{cm}}\right)$, em megapascals, e do módulo de elasticidade estático tangente inicial do concreto (Eci), em gigapascals, bem como a absorção de água (A), índice de vazios por imersão e fervura (Ivc), ambos em percentagem, e a análise da massa específica real dos corpos-de-prova ( $\rho$ r), em kg/m $\mathrm{m}^{3}$, para os concretos que atenderam à autoadensabilidade.

Tabela 4: Propriedades no estado endurecido dos concretos produzidos.

\begin{tabular}{|c|c|c|c|c|c|c|c|c|c|c|}
\hline \multirow{2}{*}{$\begin{array}{l}\text { CÓDIGOS DOS } \\
\text { CONCRETOS }\end{array}$} & \multicolumn{2}{|c|}{$\mathrm{f}_{\mathrm{cm}}(\mathrm{MPa})$} & \multicolumn{2}{|c|}{$\mathrm{E}_{\mathrm{Cl}}(\mathrm{GPa})$} & \multicolumn{2}{|c|}{ A (\%) } & \multicolumn{2}{|c|}{$\mathrm{I}_{\mathrm{vc}}(\%)$} & \multicolumn{2}{|c|}{$\rho r\left(g / \mathrm{cm}^{3}\right)$} \\
\hline & Valores & $\begin{array}{l}\text { CV } \\
\text { (\%) }\end{array}$ & Valores & $\begin{array}{l}\text { CV } \\
\text { (\%) }\end{array}$ & Valores & $\begin{array}{l}\text { CV } \\
\text { (\%) }\end{array}$ & Valores & $\begin{array}{l}\text { CV } \\
\text { (\%) }\end{array}$ & Valores & $\begin{array}{l}\text { CV } \\
\text { (\%) }\end{array}$ \\
\hline CAIB12 & 29,77 & 8,08 & 31,73 & 3,52 & 5,1 & 5,1 & 11,3 & 4,04 & 2,52 & 0,61 \\
\hline CAId1B12 & 27,07 & 18,0 & 26,01 & 10,71 & 5,7 & 1,42 & 12,5 & 1,15 & 2,50 & 1,39 \\
\hline CAId2B12 & 28,52 & 15,9 & 28,52 & 14,48 & 6,4 & 7,87 & 13,7 & 6,3 & 2,49 & 0,94 \\
\hline CAId3B12 & 31,29 & 7,52 & 27,55 & 10,27 & 4,4 & 4,08 & 9,9 & 3,48 & 2,50 & 0,45 \\
\hline CAId4B12 & 26,82 & 15,26 & 26,79 & 18,0 & 4,6 & 5,71 & 10,1 & 4,44 & 2,45 & 1,09 \\
\hline CAIB12D1 & 23,88 & 8,74 & 24,15 & 2,78 & 6,3 & 9,8 & 13,24 & 2,22 & 2,51 & 2,03 \\
\hline CMB12 & 22,82 & 4,87 & - & - & 6,2 & 5,35 & 13,7 & 4,93 & 2,55 & 0,44 \\
\hline $\mathrm{CMc} 1 \mathrm{~B} 12 \mathrm{C} 1$ & 29,08 & 5,34 & 30,32 & 17,70 & 5,9 & 6,8 & 11,4 & 4,55 & 2,16 & 1,72 \\
\hline $\mathrm{CMc} 2 \mathrm{~B} 12 \mathrm{C} 1$ & 26,76 & 10,60 & 29,55 & 14,70 & 5,1 & 2,14 & 9,7 & 2,60 & 2,16 & 2,16 \\
\hline $\mathrm{Mc} 3 \mathrm{~B} 12 \mathrm{C} 1$ & 27,11 & 12,85 & 28,99 & 12,2 & 5,3 & 5,8 & 10,2 & 5,28 & 2,17 & 2,25 \\
\hline Mc4B12C1 & 23,35 & 9,98 & 32,52 & 18,35 & 5,9 & 8,38 & 11,3 & 7,15 & 2,16 & 2,87 \\
\hline
\end{tabular}

Os resultados de resistência à compressão axial e módulo de elasticidade estático apresentaram valores significativos, tanto para os concretos produzidos com agregado miúdo natural quanto com industrial. As modificações granulométricas de acréscimo e/ou retirada de partículas de determinadas frações proporcionaram efeitos significativos nessas propriedades, atendendo-se as recomendações da NBR 6118 [37]. 


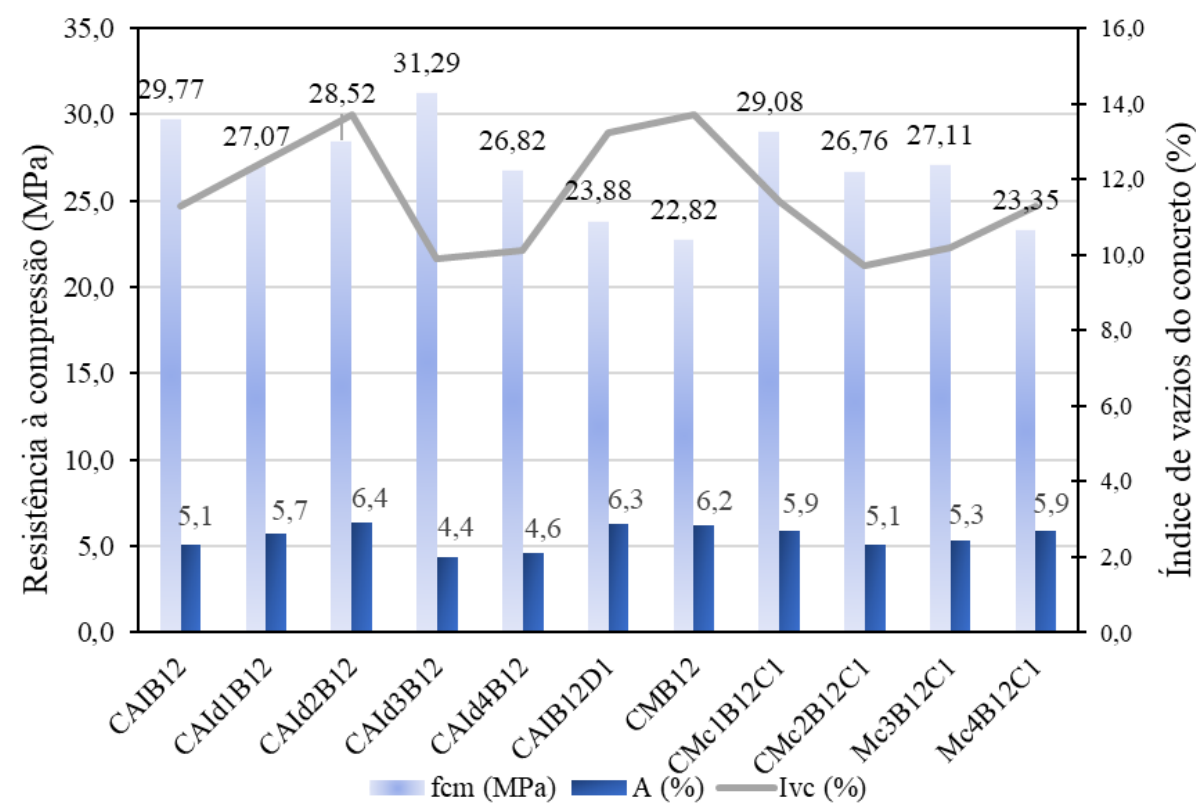

Figura 8: Valores de resistência à compressão, absorção e índice de vazios dos concretos autoadensáveis.

Entre as composições contendo areia industrial (AI), apenas CAIB12D1 (descontínua no intervalo \#6,3 - \#4,75 mm) apresentou menor valor de $\mathrm{f}_{\mathrm{cm}}$ e Eci, possivelmente devido a diminuição de $\mathrm{D}_{60}$ e aumento de $\mathrm{D}_{10}$ no parâmetro Cup, influenciando na diminuição de $P D P$. Desse grupo de composições contendo areia industrial (AI), a segunda menor resistência correspondeu a CAIB12D1, possivelmente devido a maior predominância de partículas na fração \#0,60 mm, causando o aumento de PRI das frações vizinhas, diminuindo o PDP e, consequentemente, aumentando o índice de vazios $(33,1 \%)$.

No grupo das composições contendo areia média (M), as propriedades mecânicas não apresentaram maiores discrepâncias nos valores de $\mathrm{f}_{\mathrm{cm}}$ e Eci em relação às do grupo das composições contendo AI, o que pode fazer sentido devido as proporções de graúdo e miúdo terem sido as mesmas (50\%/ $50 \%$ ). Por tratar-se de areia natural, os grãos são mais regulares e contém menos finos comparado aos grãos de areia industrial, cujo incremento de finos do pó de rocha pode estar ligado ao ganho de resistência dos CAA contendo "AI". Guimarães e Gomes [38] afirmam ter constatado um ganho de resistência mecânica dos concretos contendo os finos da areia de britagem somado aos maiores tamanhos dos grãos deste material em conjunto com a areia de rio.

No geral, houve alguns casos isolados com coeficiente de variação de $18 \%$ para os resultados de $\mathrm{f}_{\mathrm{cm}} \mathrm{e}$ Eci, entretanto, os valores apresentaram uma boa homogeneidade das misturas de acordo com o critério de Grubbs. Nas composições contendo apenas agregados naturais, o aumento constatado em Eci ocorreu, possivelmente devido às modificações ocasionadas nas frações mais grossas. A diminuição de Eci (no caso deste estudo sendo abaixo de $27 \mathrm{GPa}$ ), também foi observada por Silva Barbosa [39], os quais afirmam ser consequência da redução do esqueleto granular.

Os índices de vazios dos concretos ficaram dentro da faixa de 10 a $15 \%$, enquanto a absorção do concreto ficou entre 4,2 e $6,3 \%$, o que mostra que os CAA foram classificados como concretos normais, de acordo com Helene [35]. O refinamento da estrutura porosa resultante da granulometria modificada das composições de agregados contribuiu para esses resultados, conforme pode ser visto nas composições CAId3B12 e CAId4B12 de forma mais pronunciada. Tal fato também foi comprovado por Guimarães e Gomes [38], cujos poros preenchidos por partículas finas contribui para a menor absorção de água por imersão.

A respeito dos valores de massa específica real dos CAA, verificou-se que aqueles contendo o agregado miúdo "M" apresentaram valores inferiores aos concretos contendo o pó de rocha "AI", o que pode ter sido influenciado pela maior predominância de frações miúdas no esqueleto granular e por não haver maior incorporação de ar na produção do CAA. Tal fato refletiu em valores maiores dos parâmetros Cup e PDP dos concretos CMc2B12C1, CMc3B12C1 e CMc4B12C1. 
A percentagem de agregado graúdo (PAG) igual a 50\%, o maior índice de vazios das distribuições contínuas e descontínuas, a dimensão máxima característica dos agregados de 12,5 $\mathrm{mm}$ e os parâmetros fixos $P D P$ e $C u p$, satisfatórias para misturas de CAA (frações granulométricas menores e iguais a \#0,60 mm e com dimensão dos grãos entre \#4,75 e \#9,5 mm), foram parâmetros que contribuíram para a estabilidade das misturas de CAA.

Portanto, constatou-se que os concretos formulados com os mesmos parâmetros de dosagem (contidos na Tabela 1), mas com curvas granulométricas contínuas e descontínuas distintas, atenderam às recomendações normativas de autoadensabilidade e as propriedades no estado endurecido.

Na Tabela 5, estão contidas as recomendações para a formulação de composições de agregados para concreto autoadensável.

Tabela 5: Recomendações para formulação de composições de CAA

\begin{tabular}{c|c|c}
\hline $\begin{array}{c}\text { PREDOMINÂNCIA DE FRAÇÕES } \\
\text { GRANULOMÉTRICAS }\end{array}$ & $\begin{array}{c}\text { PARÂMETROS DE GRA- } \\
\text { DUAÇÃO }\end{array}$ & PARÂMETROS DE AUTOADENSABILIDADE \\
\hline$\leq 0,60 \mathrm{~mm}$ & PDP: $14 \pm 7$ & Espalhamento (SF): $750 \pm 50$ \\
\hline $4,75 \leq \mathrm{D}_{\mathrm{p}} \leq 9,5 \mathrm{~mm}$ & Cup: $15 \pm 4$ & Funil V (FV): $9 \pm 1$ \\
\hline & PAG: $50 \%$ & L-Box (HP): $0,8-1,0$ \\
\hline & Dmáx $=12,5 \mathrm{~mm}$ & \\
\hline
\end{tabular}

$\mathrm{Dp}=$ diâmetro da partícula

Estudos realizados mostraram que diferentes combinações de agregados para concreto autoadensável (CAA) tiveram a influência dos tamanhos dos grãos, principalmente, na região das frações fora da região intermediária, abaixo da fração \#0,60 mm e entre \#4,75 $\leq \mathrm{Dp} \leq 9,5 \mathrm{~mm}$. O uso de distintos agregados miúdos se deu justamente pela dificuldade de serem encontradas areias para tornar a distribuição mais fechada na fração intermediária, fato apenas obtido com o uso do pó de rocha.

Com o método experimental para obtenção de maior massa unitária, conseguiu-se determinar composições ótimas das combinações de agregados, entretanto, apesar desse método ser aplicado de forma satisfatória para a obtenção do empacotamento de partículas em distribuições contínuas e descontínuas, os demais parâmetros estudados PDP (predominância de diâmetro de partículas) e Cup (coeficiente de uniformidade) não foram discutidos por tal método quando aplicado ao CAA.

Os conhecimentos sobre curva granulométrica dos agregados combinados, tipos de distribuição (contínua ou descontínua), parâmetros PDP e Cup, como também a percentagem de agregado graúdo (PAG), possibilitaram encontrar as composições de agregados para CAA de modo que atendaram as propriedades de autoadensabilidade.

Conforme mostrado na Tabela 5, acima, com o espalhamento definido entre $750 \pm 50 \mathrm{~mm}$, funil $\mathrm{V}$ entre $9 \pm 1$ s e caixa L entre 0,8 e 1,0, pode-se determinar os parâmetros de graduação combinados de $P D P$ e Cup.

Tomado conhecimento desses parâmetros de graduação, a determinação experimental da massa unitária e do índice de vazios foi, então, realizada para a cada uma das composições modificadas com distintos arranjos granulares. Todo esse controle se faz necessário para não tornar excessiva a presença de frações mais grossas na mistura, visto que a viscosidade e a estabilidade do CAA podem ser afetadas.

\section{CONCLUSÕES}

Neste estudo, a questão da autoadensabilidade das misturas de concreto foi investigada, dando ênfase à avaliação dos parâmetros de graduação de agregados para obtenção de composições de CAA. Não apenas as propriedades no estado fresco, mas também as propriedades no estado endurecido foram analisadas, a partir do estudo de diferentes distribuições granulométricas submetidas a modificações de suas frações de distintos tamanhos. Baseados nos resultados apresentados, as seguintes conclusões foram pontuadas:

- As distribuições contínuas e descontinuas com concavidade mais fechada da curva granulométrica, apresentaram-se satisfatórias para CAA, quando considerados os parâmetros de graduação de agre- 
gados e a percentagem de agregado graúdo de $50 \%$;

- A descontinuidade granulométrica provocada de forma pontual não contribuiu para a perda de estabilidade da mistura, resultante da interação das partículas no efeito parede; o distanciamento de frações menores de agregados miúdos em relação aos agregados graúdos favoreceu a teoria de separação de partículas graúdas e miúdas;

- A maior quantidade de partículas finas no concreto resultou no aumento dos parâmetros $P D P$ e $C u p$ (com menores valores de $\mathrm{D}_{p \text {, médio }}$, diâmetro médio de partículas miúdas, e de $\mathrm{D}_{10}$, respectivamente), o que influenciou na melhor estabilidade da mistura e no atendimento à autoadensabilidade, principalmente em concretos onde predominaram partículas mais densas e maiores de agregados graúdos, ou seja, maiores $\mathrm{D}_{g}$, médio;

- Partículas com diâmetros mais finos aumentaram a viscosidade dos CAA, sendo identificado tal particularidade por meio do ensaio de funil-V e caixa L. O ensaio de espalhamento apresentou limitação na verificação desse quesito, embora o teste seja fundamental para análise visual das misturas;

- Concretos autoadensáveis apresentaram melhor atendimento aos critérios de autoadensabilidade quando foram considerados os parâmetros de graduação de agregados PDP $(14 \pm 7)$, Cup $(15 \pm 4)$, PAG: $50 \%$ e diâmetro máximo de $12,5 \mathrm{~m}$, bem como a predominância de tamanho de partículas $\leq$ $0,60 \mathrm{~mm}$ e entre 4,75 e $9,5 \mathrm{~mm}$;

- Nas misturas de concretos que apresentaram os parâmetros de autoadensabilidade, tais como espalhamento (SF: $750 \pm 50$ ), funil V (FV: $9 \pm 1$ ) e L-Box (HP: 0,8 - 1,0), constatou-se ganhos significativos nas propriedades do estado fresco e endurecido.

\section{AGRADECIMENTOS}

Os autores agradecem o apoio da Fundação de Amparo à Pesquisa de Alagoas (FAPEAL) pelo suporte financeiro. Também agradecem a infraestrutura disponibilizada pelo Laboratório de Estruturas e Materiais (LEMA) e ao Grupo de Materiais Ecoeficientes para a Construção Civil (Mecoeficon).

\section{BIBLIOGRAFIA}

[1] CHANG, P.K., "An approach to optimizing mix design for properties of high-performance concrete". Cement and Concrete Research, v. 34, n. 4, pp.623-629, Apr. 2004.

[2] OLIVEIRA, I.R., STUDART, A.R., PILEGGI, R.G., et al., Dispersão e Empacotamento de Partículas: Princípios e Aplicações em Processamento Cerâmico. São Paulo, Fazendo Arte Editorial, 2000.

[3] FAROKHZAD, R., MAHDIKHANI, M., BAGHERI, A., et al., "Representing a logical grading zone for self-consolidating concrete". Construction and Building Materials, v. 115, n.15, pp.735-745, July. 2016.

[4] UMA, R.N., SUGANYA, S., SARANYA, C.V., "A review on performance of self-compacting concrete using mineral and chemical admixture". International Journal of Engineering and Modern Education. pp.157-161, Apr. 2017.

[5] SANTOS, A.C.P., ORTIZ-LOZANO, J.A., VILLEGAS, N., et al., "Experimental study about the effects of granular skeleton distribution on the mechanical properties of self-compacting concrete (SCC)". Construction and Building Materials, v.78, n. 1, pp. 40-49, Mar. 2015.

[6] DÍAZ, V. O. Método de dosagem de concreto de elevado desempenho. São Paulo: Pini, 1998.

[7] GHODDOUSI, P., JAVID, A.A.S., SOBHANI, J., "Effects of particle packing density on the stability and rheology of self-consolidating concrete containing mineral admixtures". Construction and Building Materials, v. 53, n. 28, pp. 102-109, Feb. 2014.

[8] DAMINELI, B.L., PILEGGI, R.G., JOHN, V.M., "Influência do empacotamento e dispersão de partículas no consumo de cimento de concretos". Revista IBRACON de estruturas e materiais, v. 10, n. 5, pp. 9981024, Oct. 2017.

[9] PILEGGI, R.G., "Ferramentas para o estudo e desenvolvimento de concretos refratários". Tese (Dourado), UFSC/USP, São Carlos, SP, Brasil, 2001. 
[10] LOPES, H.M.T., PEÇANHA, A.C.C., CASTRO, A.L.D. Considerações sobre a eficiência de misturas de concreto de cimento Portland com base no conceito de empacotamento de partículas. Matéria, Rio de Janeiro, v. 25, n.1, 2020.

[11] DE LARRARD, F., Structures granulaires et formulation des bétons. Études et Recherches des Laboratoires des Ponts et Chaussées. Ouvrages d'art OA 34, 1999.

[12] MOOSBERG-BUSTNES, H., LAGERBLAD, B., FORSSBERG, E., "The function of fillers in concrete". Material and Structures, v. 37, n.2, pp. 74-81. 2004.

[13] MEHDIPOUR, I., KHAYAT, K.H., "Understanding the role of particle packing characteristics in rheophysical properties of cementitious suspensions: A literature review'. Construction and Building Materials. v.161, n. 10, pp. 340-353, Feb. 2018.

[14] HERMANN, A., BILCATI, G.K., AMES, I., SILVA, A.G.C.D., et al.. "Using a particle packing model considering cement as part of the" dry arrangement”. Matéria, Rio de Janeiro, v. 25, n. 04, 2020.

[15] LI, L.G., KWAN, A.K.H., "Concrete mix design based on water film thickness and paste film thickness. Cement \& Concrete Composites, v. 39, pp. 33-42, May. 2013.

[16] HAFID, H., OVARLEZ, G., TOUSSAINT, F., et. al., "Effect of particle morphological parameters on sand grains packing properties and rheology of model mortars". Cement and Concrete Research, v. 80, pp. 44-51, Feb. 2016.

[17] NEEKA, T., NGEKPE, B.E., JAJA, G.W.T. "A new mix design method for self-compacting concrete based on close aggregate packing method". SSRG International Journal of Civil Engineering, v. 6, n. 4, pp.23-33, Apr. 2019.

[18] SU, N., HSU, K-C., CHAI, H.W., "A simple mix design method for self-compacting concrete". Cement and Concrete Research, v. 31, n. 12, pp. 1799-1807, Dec. 2001.

[19] MELO, K.A., "Contribuição à dosagem de concreto autoadensável com adição de fíler calcário". Dissertação de M.Sc., UFSC, Florianópolis, SC, Brasil, 2005.

[20] TUTIKIAN, B.F., "Proposição de um método de dosagem experimental para concretos autoadensáveis". Tese de D.Sc., UFRGS, Porto Alegre, 2007.

[21] LISBOA, E.M., GOMES, P.C.C., LIMA, F.B., et al., "Concreto autoadensável uma opção para os prémoldados". In: $1^{o}$ Encontro Nacional de Pesquisa-Projeto-Produção em Concreto Pré-Moldado, São Carlos, São Paulo, Brasil, 03-04 Nov. 2005.

[22] CAVALCANTI, D.J.H. "Contribuição ao estudo de propriedades do concreto autoadensável visando sua aplicação em elementos estruturais”. Dissertação de M.Sc., UFAL, Maceió, Al, Brasil, 2006.

[23] MONTEIRO, R., GOMES, P.C.C., MELO, K.A., "Composições de agregados para obtenção de concreto autoadensável”. In: IV Congresso Ibero Americano sobre Betão Auto-Compactável - BAC2015, pp. 205-214, July 2015.

[24] GOMES, P.C.C. "Optimization and characterization of high-strength self-compacting concrete". Tese de D.Sc., Universitat Politécnica de Catalunya, UPC, Espanha, 2002.

[25] OKAMURA, H., OUCHI, M. "Self-compacting concrete". Journal of Advanced Concrete Technology Japan Concrete Institute, v. 01, n.1, pp. 5-15, Apr. 2003.

[26] ASSOCIAÇÃO BRASILEIRA DE NORMAS TÉCNICAS. NBR 16697: Cimento Portland - Requisitos, Rio de Janeiro - RJ, 2018.

[27] ASSOCIAÇÃO BRASILEIRA DE NORMAS TÉCNICAS. NBR 7211: Agregados para concreto - Especificação, Rio de Janeiro, 2009, 9p.

[28] MELO, C.V.A., "Avaliação e determinação de parâmetros para otimização de esqueleto granular em atendimento à autoadensabilidade de concretos". Tese de D.Sc, UFAL, Maceió, Al, 2019.

[29] MELO, C.V.A., GOMES, P.C.C., MORAES, K.A.M. "Um estudo de parâmetros de empacotamento que influenciam as propriedades no estado fresco do concreto autoadensável". Cerâmica, v. 65, n. 375, pp. 432442, Aug. 15, 2019. 
[30] ASSOCIAÇÃO BRASILEIRA DE NORMAS TÉCNICAS. NBR NM 45: Agregados - Determinação da massa unitária e do volume de vazios, Rio de Janeiro, 2006.

[31] ASSOCIAÇÃO BRASILEIRA DE NORMAS TÉCNICAS. NBR 15823-1: Concreto autoadensável: Parte1: Classificação, controle e recebimento no estado fresco. Rio de Janeiro, 2017.

[32] ASSOCIAÇÃO BRASILEIRA DE NORMAS TÉCNICAS. NBR 5739: Concreto - Ensaio de compressão de corpos de prova cilíndricos - Métodos de ensaio, Rio de Janeiro - RJ, 2018.

[33] ASSOCIAÇÃO BRASILEIRA DE NORMAS TÉCNICAS. NBR 5738: Concreto - Procedimento para moldagem e cura de corpos de prova, Rio de Janeiro - RJ, 2015.

[34] ASSOCIAÇÃO BRASILEIRA DE NORMAS TÉCNICAS NBR 8522: Concreto - Determinação dos módulos estáticos de elasticidade e de deformação à compressão, Rio de Janeiro - RJ, 2017.

[35] ASSOCIAÇÃO BRASILEIRA DE NORMAS TÉCNICAS. NBR 9778: Argamassa e concreto endurecidos - Determinação da absorção de água, índice de vazios e massa específica, Rio de Janeiro - RJ, 2005.

[36] HELENE, P.R.L. “https://orcid.org/0000-0002-8541-5998”. Tese de D.Sc, USP, São Paulo, 1993.

[37] ASSOCIAÇÃO BRASILEIRA DE NORMAS TÉCNICAS. NBR 6118: Projetos de Estrutura de Concretos - Procedimentos. São Paulo, 2014.

[38] GUIMARÃES, C., GOMES, M.V.A. "Areia de britagem como alternativa à areia natural na confecção de concreto: um panorama sobre o estado da arte". Labor e Engenho, v. 14, p. e020005-e020005, 2020.

[39] SILVA BARBOZA, L., OLIVEIRA, W.A.; SOUZA, L.C., et al. "Análise da Influência do Teor de Argamassa nas Propriedades Mecânicas e Reológicas do Concreto Autoadensável". Revista de Engenharia e Pesquisa Aplicada, v. 6, n. 1, p. 22-33, 2021.

\section{ORCID}

Cássia Vanessa Albuquerque de Melo

Paulo César Correia Gomes

Karoline Alves de Melo Moraes https://orcid.org/0000-0002-8541-5998

https://orcid.org/0000-0002-8892-3058

https://orcid.org/0000-0002-3168-3313 